\title{
Journal of \\ Challenging look at therapeutic trend of chronic kidney disease-mineral bone disorder in children
}

\author{
Afshin Safaei-Asl ${ }^{*}$
}

T

reatment of mineral bone disorders in children with chronic kidney disease (CKD) is very important. It requires a specific view to achieve adequate growth process and prevention of cardiovascular disease. The regulation of bone and mineral homeostasis is one of the main challenges in children with chronic renal failure, while the ideal control of this problem is not entirely acceptable so far. In children, no unique consensus for administration of newer phosphate-binders to manage chronic kidney disease-mineral bone disorder (CKD-MBD) existed. This is due to limited clinical evidences in this group of patients. One of the pivotal issues in management of CKDMBD in this group is the control of serum phosphorus levels. These therapeutic strategies for management of hyperphosphatemia are based on their values and changes in calcium and phosphorus homeostasis based on the age of children. According to recent 2017 KDIGO CKD-MBD guideline, children with CKD grade 3A (GFR; 45-59 mL/ $\left.\mathrm{min} / 1.73 \mathrm{~m}^{2}\right)$ to grade $5 \mathrm{D}\left(\mathrm{GFR}<15 \mathrm{~mL} / \mathrm{min} / 1.73 \mathrm{~m}^{2}\right.$ on dialysis), should be treated with phosphate-lowering agents according to serum calcium levels $(1,2)$. In this group, we have also a therapeutic strategy with noncalcium based phosphate-binding compounds, including sevelamer hydrochloride $\left(\right.$ Renage $\left.^{\circledR}\right)$ and sevelame carbonate $\left(\left(\right.\right.$ Renvela $\left.^{\circledR}\right)$. They have been widely administered in children with CKD successfully. Both of these drugs help to control of hyperphosphatemia without increasing serum calcium. Sevelamer carbonate has not been studied in pediatric patients below six years of age. Iron-based phosphate binders have not been studied in children too. Nicotinamide by reducing the absorption of phosphorus in the gastrointestinal tract effectively decreases serum phosphorus concentrations. However, more comprehensive studies on the effect of this drug in children is necessary. The safety and efficacy of lanthanum carbonate in children have not been proven. Long-term administration of this drug has been associated with its precipitation in the long bones, especially in the growth plate. Currently lanthanum carbonate is not recommended in children (3). According to vitamin D deficiency in children with chronic renal failure, the recommended doses of vitamin D in children are not based on KDIGO criteria, while its administration in accordance with

\begin{abstract}
Implication for health policy/practice/research/medical education CKD-MBD explains disturbances of calcium, phosphorus, $\mathrm{PTH}$, and vitamin $\mathrm{D}$ metabolism in CKD patients. The target management of CKD-MBD is to manage secondary hyperparathyroidism and avoid the development of extraskeletal calcifications. The treatment of these problems in children needs a specific view to achieve adequate growth process and prevention of cardiovascular problems.

Keywords: Chronic kidney disease, Mineral bone disorder, children, Treatment
\end{abstract}

body size and the growth trend of children leads to its inadequate prescribing in children. On the other hand, the administration of high doses of calcitriol can be associated with the risk of increasing the calcium-phosphorus product and calcification outside of the bone. In addition, other vitamin D analogues, such as paracalcitol and doxercalciferal, are less commonly administered in children due to the high cost, inaccessibility and data limitations. However, the paracalcitol can be administered in children over five years old in the dialysis phase. Calcitriol and doxercalciferol are equivalent in controlling bone turnover $(4,5)$. There are also very limited studies in pediatric patients on administration of calcimimetic agents. In pediatric CKD patients in stages 4 and 5, limited studies have been conducted on the tolerance and effects of cinacalcet on calcium and PTH metabolism. However, due to side effects on longitudinal growth, cautions on its administration in children is essential. Hence, administration of cinacalcet requires broader and more comprehensive studies (6).

\section{Author's contribution \\ AS is the single author of the paper.}

Conflicts of interest

The author declared no competing interests.

Ethical considerations

Ethical issues (including plagiarism, misconduct, data fabrication, falsification, double publication or 
submission, redundancy) have been completely observed by the author.

\section{Funding/Support}

None.

\section{References}

1. Ketteler M, Block GA, Evenepoel P, Fukagawa M, Herzog CA, McCann L, et al. Kidney Disease: Improving Global Outcomes (KDIGO) CKD-MBD Update Work Group. KDIGO 2017 Clinical Practice Guideline Update for the Diagnosis, Evaluation, Prevention, and Treatment of Chronic Kidney Disease-Mineral and Bone Disorder (CKD-MBD). Kidney Int Suppl. 2017; 7:1-59

2. Ketteler M, Block GA, Evenepoel P, Fukagawa M, Herzog CA, McCann L, et al. Executive summary of the 2017 KDIGO Chronic Kidney Disease-Mineral and Bone Disorder (CKD-MBD) Guideline Update: what's changed and why it matters. Kidney International. 2017;92:26-36. doi:10.1016/j.kint.2017.04.006

3. Hanudel MR, Salusky IB. Treatment of pediatric chronic kidney disease-mineral and bone disorder. Curr Osteoporos Rep. 2017;15:198-206. doi: 10.1007/s11914-017-0365-0.

4. Wesseling-Perry K, Pereira RC, Sahney S, Gales B, Wang HJ, Elashoff R, et al. Calcitriol and doxercalciferol are equivalent in controlling bone turnover, suppressing parathyroid hormone, and increasing fibroblast growth factor-23 in secondary hyperparathyroidism. Kidney Int. 2011;79:112-9. doi: 10.1038/ki.2010.352.

5. Webb NJ, Lerner G, Warady BA, Dell KM, Greenbaum LA, Ariceta G, et al. Efficacy and safety of paricalcitol in children with stages 3 to 5 chronic kidney disease. Pediatr Nephrol. 2017;32(7):1221-32. doi: 10.1007/s00467-0173579-6.

6. Alharthi AA, Kamal MN, Abukhatwah MW, Sherief ML. Cinacalcet in pediatric and adolescent chronic kidney disease. A single-center experience. Medicine. 2015;94:1-7. doi: 10.1097/MD.0000000000000401.

Please cite this paper as: Safaei-Asl A. Challenging look at therapeutic trend of chronic kidney disease-mineral bone disorder in children. J Parathyr Dis. 2018;6(1):5-6. DOI: 10.15171/jpd.2018.03.

Copyright (c) 2018 The Author(s); Published by Nickan Research Institute. This is an open-access article distributed under the terms of the Creative Commons Attribution License (http://creativecommons.org/licenses/by/4.0), which permits unrestricted use, distribution, and reproduction in any medium, provided the original work is properly cited. 